\title{
APPROPRIATE SAMPLE FOR TECHNOLOGY ADOPTION STUDIES IN TECHNICAL EDUCATION
}

\author{
Shannon W. Beasley, Middle Georgia State University, shannon.beasley@mga.edu
}

\begin{abstract}
The aim of this study is to determine if a significant difference exists between the responses obtained from students and faculty engaged in technical education when deciding to adopt and use technology in the classroom. Surveying a representative population is critical when supporting interventions by administrators that will promote the adoption of technologies with proven advantages. Data was gathered by sending a questionnaire (53 questions) based on an extension of the Technology Acceptance Model to 7, 665 students and 445 faculty of a southeastern technical college during the fall semester of 2015. Analysis of the data was not able to support a conclusion that significant differences exist between the results obtained from faculty and students. This suggests that it is reasonable to use students and faculty as respondents in surveys related to technology adoption in technical education.
\end{abstract}

Keywords: student samples, Technology Adoption Model (TAM), technical education, Unified Theory of Acceptance and Use of Technology (UTAUT), volitional control, decision-making

\section{INTRODUCTION}

Many teachers attempt to transact higher education by establishing a common ground that allows students and teachers to communicate freely and comfortably in a mutually accepted environment. This desired outcome creates a common ground by using communication paths that are accepted by both sides of the information interchange (Arkoudis, S., Watty, K., Baik, C., Yu, X., Borland, S., Lang, I. Lang, J., \& Pearce, A., 2013). On the surface, it would appear this mutual agreement results from the compromise between the perceived opinions of students and teachers, but the situation can be greatly simplified if there is no difference in perception of acceptable technology between the two groups of actors engaged in higher education. The initial consideration of technology acceptance put forward by Davis in 1989 postulates that the decision to adopt technology in a population with volitional control in the decision-making process could be predicted by considering perceived usefulness (PU), perceived ease of use (PEoU), and attitude toward using technology. As this framework evolved over subsequent studies, many academics argued that the framework becomes distorted when researchers use students as a sample (Venkatesh \& Bala, 2008; Venkatesh, Thong, $\& \mathrm{Xu}, 2012)$. The rationale being that students have no volitional control in the decision-making process and are not analogous to the members of the actual population of interest. However, in the case of technical education, the expressed goal is to make a selection of technology that is acceptable to both students and teachers. Using a sample composed of both students and teachers is valid if there is no significant difference found in the survey results obtained from both groups when using the same survey instrument.

The factors that influence the decision to adopt technology in the classroom are of particular interest to technical college leadership and administration that seek to stage interventions to promote the adoption of desirable technology (Kanthawongs, 2011; Venkatesh \& Bala, 2008). Technology is deemed desirable for adoption when it advances the interests of stakeholders involved in the transaction of technical education (Blaskovich, 2008; Soffer, Nachmias, \& Ram, 2010). Given the fact that technical education is tasked with preparing the workforce of a given area or region within a state, the group of stakeholders for a technical college is comprised of students, faculty members, college administrators, employers of future graduates, and members of the community that the employers serve (Borrego, Froyd, \& Hall, 2010; TCSG, n.d.).

The adoption and subsequent use of technology in the classroom can produce value for stakeholders by allowing the creation and use of reusable content, accommodating multiple learning styles, and supporting the removal of spatial and temporal elements that restrict learning opportunities for students (Luan \& Teo, 2009; Ormerod \& Rosewell, 


\section{Issues in Information Systems \\ Volume 20, Issue 1, pp. 32-39, 2019}

2009; Schulte, 2010; Shoham \& Perry, 2009). Researchers have estimated that the technology used in the actual workforce is two years ahead of the technology adopted for use in the college classroom (Murray, 2008). In light of this estimated lag between what is used in industry and what is taught in the classroom, it is necessary to allow students to study and learn with the least amount of delay possible to avoid increasing the gap between student and practitioner (Kanthawongs, 2011; Türel \& Johnson, 2012).

One of the most popular research instruments used to study and explain the adoption of technology is the Technology Acceptance Model (TAM) proposed by Davis in 1989. The original framework is used to explain the decision to adopt technology as a process predicted by the three factors perceived usefulness (PU), perceived ease of use (PEoU), and attitude toward computer use (ATCU) (Davis, 1989). Many researchers have sought to expand the predictive power of this model over the years by adding additional predictive elements such self-efficacy (SE), subjective norm (SN), various assessments of quality, administrative support, and many other factors. Also, TAM studies slowly began to drop the requirement that a respondent must have the perception that they possess a level of volitional control in the decision-making process that will allow the respondent to actually make a decision with respect to technology adoption (Venkatesh, Morris, Davis, \& Davis, 2003). As TAM research evolved, new versions of the framework emerged such as Technology Acceptance Model 2 (TAM2), Technology Acceptance Model 3 (TAM3), Unified Theory of Acceptance and Use of Technology (UTAUT), and many others (Venkatesh \& Bala, 2008; Venkatesh, Thong, \& Xu, 2012).

When reviewing the work carried out in technology adoption studies, it is noted that some experts criticize the results obtained from studies that use samples composed of college students (Venkatesh, et al, 2003; Yousafzai, Foxall, and Pallister, 2010). In many cases, researchers use students as an easily accessible sample of convenience to conduct a study. However, these criticisms of student samples are valid only if the sample populations differ significantly from the actual populations of interest that are being evaluated in the study (James \& Sonner, 2001).

Assumptions are held by many people that other demographic groups are unlike their own demographic group in terms of opinions, perceptions, likes, dislikes, and aptitude with respect to technology (Vodanovich, Sundaram, \& Myers, 2010). As a general rule, this assumption is no more dangerous than any other type of stereotyping until the individual affected by bias decides to make decisions or act based on factors that stem from the assumption. This potential bias is particularly dangerous in fields that are subject to perception-based factors that are vulnerable to false assumptions based on various types of perceived differences. One such field of particular interest is the study of technology adoption.

\section{PURPOSE OF THE STUDY}

The purpose of this study is to determine if there is a significant difference in answers obtained from students and faculty members at a technical college when completing the survey related to technology adoption. In this study, data obtained from a previous research project investigating the decision to adopt technology while transacting technical education is analyzed to determine if significant differences exist between survey results collected from faculty and students within the sample. Both groups, faculty, and students, were asked to answer the questions from the same survey instrument. Neither group was given additional explanation or instructions that was withheld from the other group.

Consistent with its purpose, the following question was asked:

Question: Is there a difference between the results provided by teachers and students for the variables when surveyed?

Based on this question, the following hypotheses were stated:

$H_{0}$ : There is no significant difference between survey results obtained from a faculty sample and a student sample within a technical college for the predictor variables perceived usefulness, perceived ease of use, subjective norm, self-efficacy, system quality, information quality, service quality, and intent to use. 


\section{Issues in Information Systems \\ Volume 20, Issue 1, pp. 32-39, 2019}

$H_{1}$ : There is a significant difference between survey results obtained from a faculty sample and a student sample within a technical college for the predictor variables perceived usefulness, perceived ease of use, subjective norm, self-efficacy, system quality, information quality, service quality, and intent to use.

The analysis conducted in this study addresses the appropriateness of using students as a sample in the area of technology adoption with respect to transacting technical education. Because students are actual stakeholders in the population of interest, this study cannot be extended to answer the overall criticism that students are not appropriate sample participants for many technology adoption studies. In this case, the intent is to show that students are appropriate to include as respondents in a sample for investigating the factors that lead to the decision to adopt technology for transacting technical education.

\section{BACKGROUND}

At the time that the survey was conducted, technical education in Georgia was provided by 27 colleges that made up the Technical College System of Georgia (TCSG). Each of these 27 colleges had been charged with providing General Educational Development (GED) classes, occupational training, and core college classes to students within an assigned coverage area (TCSG, n.d.). Classes within the various programs that were offered had designated student learning outcomes and course topics established by a state level consortium, but each teacher had the academic freedom to transact the exchange of information in the manner the individual faculty member deemed most appropriate.

In many cases, technical college instructors have not been formally educated to teach and are not required to possess any education certification. Most technical college faculty are considered qualified to teach because of a combination of education in their field, work experience in the industry, and expertise with the practical application of a particular job role (Bazile \& Walter, 2009; Bogner, 2008). Many technical college instructors have retired from their previous field of employment and have returned to teach as a second career (Olson \& Spidell, 2008). The majority of these faculty members develop their skills as educators by drawing on their own college experience or they are trained by co-workers (Bogner, 2008; Morgan \& Parr, 2009).

This lack of formal training leaves new instructors depending upon the advice of mentors and trial and error in the classroom. Given the nature of a trial and error approach, instructors must observe what not only educates but pleases students to guarantee retention and success as students move through a program (Kanthawongs, 2011; Olson \& Spidell, 2008). As a result, instructors seek to select technology solutions that satisfy their needs for delivering instruction while also satisfying the learning styles of the students (Kanthawongs, 2011). The average career of a technical college instructor is 14.5 years which lends explanation to the need for administrators to promote the adoption of educational technology (Olson \& Spidell, 2008. In a shorter than a normal career in education, there is an increased need to develop technology-enhanced content delivery as soon as possible after becoming an instructor.

\section{METHODOLOGY}

\section{Instrument Survey}

The original survey was designed to investigate the predictor variables that led to the decision to adopt technology for transacting technical education (Wang \& Wang, 2009). With the permission of Wang and Wang (2009), their instrument was used for this study by adding additional demographic questions specific to the technical college population of interest. The researcher wanted to better identify the factors that lead to technology adoption in technical education in an effort to support interventions that would promote the adoption of educational technology in technical education. To conduct the actual survey a model derived by modifying the TAM framework and a survey instrument developed by Wang \& Wang (2009) was employed. The study utilized perceived usefulness (PU), perceived ease of use (PEoU), subjective norm (SN), self-efficacy (SE), system quality (SQ), information quality (IQ), service quality (SeQ), and intent to use (ITU) as predictor variables used to describe the resulting decision toward the adoption of a given technology. 


\section{Issues in Information Systems \\ Volume 20, Issue 1, pp. 32-39, 2019}

The variables' definitions are as follows. Perceived Usefulness (PU) is defined as the decision-maker's opinion of whether the use of the given technology will produce a favorable outcome when solving a task (Ahmad, Madarsha, Zainuddin, Ismail, and Nordin, 2010). Perceived Ease of Use (PEoU) is defined as the perceived minimal level of effort needed to achieve a desired task by the decision-maker (Ahmad, et al, 2010). Subjective Norm (SN) is defined as the decision-maker's perceived level of influence exerted on the decision-maker to adopt a given technology (Wang \& Wang, 2009). Self-efficacy (SE) is defined as the decision-maker's level of confidence with achieving success using a technology (Wang \& Wang, 2009). System Quality (SQ) is defined as the decision-maker's perceived level of performance of a given technology (Wang \& Wang, 2009). Information Quality (IQ) is defined as the decisionmaker's perceived usefulness, accuracy or quality of the outcomes produced by a given technology (Wang \& Wang, 2009). Service Quality ( $\mathrm{SeQ})$ is defined as the decision-maker's perceived level of support available when using a given technology (Wang \& Wang, 2009). Intent to Use (ITU) is defined as the decision-maker's overall disposition toward using a system to achieve a desired goal (Wang \& Wang, 2009).

The survey itself contained 53 total questions. Four of the questions were added to collect demographic information about respondents. The other 49 questions were from Wang and Wang's (2009) survey. The 49 questions corresponded to the 8 predictor variables of interest in the study. (See Appendix A)

\section{Sample \& Procedure}

Prior to contact respondents, applications were filed with the Institutional Review Boards (IRBs) of the researcher's institution and the institution where faculty and students were proposed to be surveyed. After satisfying all requirements imposed by both institutions and obtaining approval of both IRBs, the institution being surveyed sent a spreadsheet containing the e-mail addresses of eligible participants for the semester of fall 2015 . The survey requests were sent to 8,110 potential respondents composed of faculty and students from Central Georgia Technical College (CGTC) located in Macon, Georgia and Warner Robins, Georgia. Of the potential respondents solicited to participate, 7,665 were students and 445 were faculty members. After a period of 2 weeks allowed for participation, 458 complete and usable surveys had been collected. The demographic composition of the respondents can be seen in Table 1.

Table 1. Demographics $(\mathrm{N}=458)$

\begin{tabular}{|l|l|l|}
\hline Position & & \\
\hline & Student & $77.5 \%$ \\
\hline & Instructor & $19.58 \%$ \\
\hline & Administrator & $1.25 \%$ \\
\hline & Support Staff & $1.66 \%$ \\
\hline Gender & & \\
\hline & Male & $25.83 \%$ \\
\hline Education & Female & $74.16 \%$ \\
\hline & & \\
\hline & $\begin{array}{l}\text { GED/High } \\
\text { School }\end{array}$ & $59.17 \%$ \\
\hline & Associate & $19.58 \%$ \\
\hline & Bachelor & $6.25 \%$ \\
\hline & Master & $14.16 \%$ \\
\hline & Doctorate & $0.08 \%$ \\
\hline
\end{tabular}

\section{Data Analysis}

For each of the predictor variables perceived usefulness, perceived ease of use, subjective norm, self-efficacy, system quality, information quality, service quality, and intent to use an independent samples t-test is used to determine if there is a significant difference between the values obtained from the two groups. The null hypothesis will be accepted or rejected using the significance level of 0.05 . Norusis (2008) suggest this type of analysis is appropriate to determine if there is a significant difference between results obtained from two distinct groups. 


\section{RESULTS}

As noted earlier, it is generally the goal of technical college instructors to select a technology solution for transacting technical education that satisfies the needs of the instructor and the student. It is in this decision-making process that the question of interest arises - Do students and instructors differ in how they decide in favor or against technology used in the classroom? The purpose of this study is to determine if there is a significant difference in answers obtained from students and faculty members at a technical college when completing the survey related to technology adoption.

The following hypotheses were stated:

$H_{0}$ : There is no significant difference between survey results obtained from a faculty sample and a student sample within a technical college for the predictor variables perceived usefulness, perceived ease of use, subjective norm, self-efficacy, system quality, information quality, service quality, and intent to use.

$H_{l}$ : There is a significant difference between survey results obtained from a faculty sample and a student sample within a technical college for the predictor variables perceived usefulness, perceived ease of use, subjective norm, self-efficacy, system quality, information quality, service quality, and intent to use.

Table 2 shows that there is insufficient evidence to reject the null hypothesis at the $95 \%$ confidence interval for any of the 8 predictor variables considered in the study. The inability to reject the null hypothesis for any of these variables suggests that similar results are likely to be found using a sample composed of students, faculty, or students plus faculty.

Table 2. Independent Samples T-test $(\mathrm{N}=458)$

\begin{tabular}{|c|c|c|c|}
\hline & Sig. & $\mathrm{df}$ & $\begin{array}{c}\text { Sig. (2- } \\
\text { tailed) }\end{array}$ \\
\hline IQ & 0.07 & 238 & 0.29 \\
\hline SQ & 0.08 & 238 & 0.63 \\
\hline SeQ & 0.63 & 238 & 0.13 \\
\hline SE & 0.02 & 105.67 & 0.35 \\
\hline SN & 0.96 & 238 & 0.10 \\
\hline PEoU & 0.11 & 238 & 0.29 \\
\hline PU & 0.29 & 238 & 0.48 \\
\hline ITU & 0.86 & 238 & 0.48 \\
\hline
\end{tabular}

\section{CONCLUSION}

The results support the assertion that the predictors (PU, PEoU, SN, SE, SQ, IQ, SeQ, and ITU) that influence instructors in technical education to adopt technology are essentially the same predictors that lead students to choose to use and embrace the same technology. This observation should allow the decision-maker to feel more confident by knowing that the evaluative criteria for judging the success of a technology acceptance decision is essentially the same on both sides of the lectern.

Since there was insufficient evidence to reject the null hypothesis and conclude that a significant difference between the two groups existed, it is reasonable to assert that college students do constitute a valid sample when investigating technology adoption in technical education. This should not be terribly surprising considering that the students are stakeholders in the decision to adopt technology in the transaction of technical education. 


\section{Issues in Information Systems \\ Volume 20, Issue 1, pp. 32-39, 2019}

\section{FUTURE WORK \& LIMITATIONS}

The Technology Acceptance Model unlocks a myriad of information that allows leaders to remove barriers and smooth the bumps in the road to facilitate technology adoption. As this study shows, not every population or sample is created equal so to speak. Previous researchers have taught us that the TAM becomes more robust and increases its predictive power when tailored to describe the workings of the population being studied. It is with this observation that suggested future research should include extending this study to include a sample composed of university students and professors using the same survey instrument from this current study. The information from a university study would provide insight into the differences in opinions about technology adoption between professors and university students as well as allowing the comparisons of technical college instructors and university professors or technical college students and university students.

Additionally, future studies can move forward by dividing the opinions collected in a more granular fashion by considering more groupings than just students and teachers. Given the ease of repeating the study in multiple samples, comparisons can be made to determine if the field of study has an effect on the willingness to embrace technology.

The researcher of this study does make the assumption that the school selected as a sample is reasonably similar in composition of students, faculty, and programs offered at other schools within the parent system or population of interest. Once this assumption is made, the study does use a sample of convenience. Another limitation is inherent to all TAM studies and comes from the study of perceptions and the true amount of volitional control actually possessed by respondents (Davis, 1989; Venkatesh, Thong, \& Xu, 2012).

\section{REFERENCES}

Ahmad, T., Madarsha, K., Zainuddin, A., Ismail, A. \& Nordin, M. (2010). Faculty's acceptance of computer based technology: Cross-validation of an extended model. Australasian Journal of Educational Technology, 26(2), 268-279. www.ascilite.org.au/ajet/

Arkoudis, S., Watty, K., Baik, C., Yu, X., Borland, H., Chang, S., Lang, I., Lang, J., \& Pearce, A. (2013). Finding common ground: enhancing interaction between domestic and international students in higher education. Teaching in Higher Education, 18(3), 222-235. http://dx.doi.org/10.1080/13562517.2012.719156.

Bazile, S., \& Walter, R. (2009). Certification of postsecondary career and technical instructors: Issues for debate. Journal of Industrial Teacher Education, 45(3), 105-112. http://scholar.lib.vt.edu/ejournals/JITE/

Blaskovich, J. (2008). Exploring the effect of distance: An investigation of virtual collaboration, social loafing, and group decisions. Journal of Information Systems, 22(1), 27-46. doi: 10.2308/jis.2008.22.1.27

Bogner, L. (2008). Using lesson study as an instrument to find the mental models of teaching and learning held by career and technical education instructors. The International Journal of Learning, 15(1), 239-244. http://thelearner.com/publications/journal

Borrego, M. Froyd, J., \& Hall, T. (2010). Diffusion of Engineering Education Innovations: A survey of awareness and adoption rates in U.S. engineering departments. Journal of Engineering Education, 99(3), 185-207. doi: $10.1002 / \mathrm{j} .2168-9830.2010 . t b 01056 . x$

Davis, F. (1989). Perceived usefulness, perceived ease of use, and user acceptance of information technology. MIS Quarterly, 13(3), 319-340. doi: 10.2307/249008

James, W. L., \& Sonner, B. S. (2001). Just say no to traditional student samples. Journal of Advertising Research, 41(5), 63-71.

Kanthawongs, P. (2011). Technology acceptance model and motivational model contributing to student satisfaction in erp-simulated web-enhanced course. Review of Business Research, 11(1), 117-121. 


\section{Issues in Information Systems}

Volume 20, Issue 1, pp. 32-39, 2019

http://www.iabe.org/domains/iabe/journal.aspx?journalid=5

Luan, W. \& Teo, T. (2009). Investigating the technology acceptance among student teachers in Malaysia: An application of the Technology Acceptance Model (TAM). The Asia-Pacific Education Researcher, 18(2), 261-272. doi: 10.3860/taper.v18i2.1327

Morgan, C., \& Parr, B. (2009). Using technology to increase collaboration between tech and core subject teachers. Techniques (Association for Career and Technical Education), 84(8), 48-52. https://www.acteonline.org/techniques/\#.UeRMlHett20

Murray, G. (2008). On the cutting edge (of Torpor): Innovation and the pace of change in American higher education. AACE Journal, 16(1), 47-61. http://www.aace.org/pubs/

Norusis, M.,J. (2008). SPSS Statistics 17.0 Guide to Data Analysis. Chicago, Il: Prentice Hall, Inc.

Olson, S., \& Spidell, C. (2008). An update: Preparation and credentialing requirements of two-year college technical instructors: A national study. Journal of Industrial Teacher Education, 44(4), 42-61. http://scholar.lib.vt.edu/ejournals/JITE/

Ormerod, P. \& Rosewell, B. (2009). Innovation, diffusion, and agglomeration. Economics of Innovation and New Technology, 18(7), 695-706. doi: 10.1080/10438590802564659

Polites, G. L., \& Karahanna, E. (2012). Shackled to the status quo: the inhibiting effects of incumbent system habit, switching costs, and inertia on new system acceptance. MIS Quarterly, 36(1), 21-A13. http://www.misq.org/

Schulte, M. (2010). Faculty perceptions of technology distance education transactions: Qualitative outcomes to inform teaching practices. The Journal of Educators Online, 7(2), 1-34. http://www.thejeo.com/

Shoham, S., \& Perry, M. (2009). Knowledge management as a mechanism for technological and organizational change management in Israeli universities. Higher Education, 57, 227-246. doi; 10.1007/s10734-008-9148y

Soffer, T., Nachmias, R., \& Ram, J. (2010). Diffusion of web supported instruction in higher education - The case of Tel Aviv University. Educational Technology \& Society, 13(3), 212-223. http://www.ifets.info/

Technical College System of Georgia (TCSG). (n.d.). Retrieved from http://www.tcsg.edu

Türel, Y., \& Johnson, T. E. (2012). Teachers' belief and use of interactive whiteboards for teaching and learning. Journal of Educational Technology \& Society, 15(1), 381-394. http://www.ifets.info/

Venkatesh, V., \& Bala, H. (2008). Technology Acceptance Model 3 and a research agenda on interventions. Decision Sciences, 39(2), 273-315. doi: 10.1111/j.1540-5915.2008.00192.x

Venkatesh, V., Morris, M. G., Davis, G. B., \& Davis, F. D. (2003). User acceptance of information technology: toward a unified view. MIS Quarterly, 27(3), 425-478. http://www.misq.org/

Venkatesh, V., L. Thong, J. Y., \& Xu, X. (2012). Consumer acceptance and use of information technology: extending the unified theory of acceptance and use of technology. MIS Quarterly, 36(1), 157-178. http://www.misq.org/

Vodanovich, S., Sundaram, D., \& Myers, M. (2010). Digital native and ubiquitous information systems. Information Systems Research, 21(4), 711-723.

Wang, W., \& Wang, C. (2009). An empirical study of instructor adoption of web-based learning systems. Computers \& Education, 53(3), 761-774. doi: 10.1016/j.compedu.2009.02.021 


\section{Issues in Information Systems}

Volume 20, Issue 1, pp. 32-39, 2019

Yousafzai, S., Foxall, G., \& Pallister, J. (2010). Explaining Internet banking behavior: Theory of Reasoned Action, Theory of Planned Behavior, or Technology Acceptance Model? Journal of Applied Social Psychology, 40(5), 1172-1202. doi:10.1111/j.15591816.2010.00 